\title{
EL MICROLEASING COMO ALTERNATIVA PARA EL FOMENTO DE LAS MICRO, PEQUEÑA Y MEDIANA EMPRESA (MIPYMES)
}

Astralia Cruz Picón*

Resumen 2012.

Este artículo está basado en el Microleasing y su viabilidad para las Mipymes durante el año

Al estudiar las Mipymes se encontró algunas debilidades, sin superar durante décadas, han disminuido su capacidad para acceder al financiamiento, para competir en el mercado internacional y comercializar sus productos, entre otras. Los resultados indican que las Mipymes, solamente han logrado mantenerse subsistiendo en medio de la crisis económica. La aplicación del Microleasing ha sido fructífera, sin embargo en el proyecto de ley, no se incluyen como sujetos de este contrato.

Algunas de las principales conclusiones del estudio son:

Se destaca el Leasing o Arrendamiento financiero como un instrumento que se ha utilizado para financiar bienes, fundamentalmente muebles, tales como: maquinarias agrícolas, equipos, vehículos etc., su eje fundamental es la financiación; una vez producida la compra entre el proveedor y el propietario (Arrendador), éste cede el bien adquirido a un Arrendatario durante un determinado período de tiempo, recibiendo un pago periódico, estableciendo al finalizar el contrato, la opción a la compra del bien.

Se destaca la necesidad de la inclusión en el proyecto de Ley de Leasing de artículos específicos para la regulación del Microleasing.

El principal beneficio del Microleasing es la atenuación de los requerimientos de garantía.

Los contratos de Leasing utilizados por Finarca y Bancentro son contratos de adhesión, contienen cláusulas abusivas en cuanto a la responsabilidad del Arrendador sobre los riesgos, y derechos del Arrendatario.

Palabras Claves: Pequeñas, Medianas Empresa, Crédito, desarrollo, opción a compra.

\section{Abstract}

This article is based on the Microleasing and its feasibility is based on the Mipymes during 2012.

By studying Mipymes it was found some weaknesses, without overcome during décadas, have decreased their ability to access funding, to compete in the international market, and marketing their products, among others. The results indicate that Mipymes, have only managed to stay subsisting in the midst of economics crisis. The application has been fruitful, however in the draft Law of Leasing, are not included as subjects in this contract.

Some of the main conclusions of the study are:

Leasing has been highlighted as an instrument that has been used to found goods, mainly furniture, such as agricultural machinery, equipment, vehicles, etc., its main focus is on funding; once the purchase between supplier and owner (lessor) has been done, this gives the property acquired to a leaser during a certain period of time, receiving a periodical payment and establishing purchase option when contract ended.

The need for inclusions is emphasized in the draft Law on Leasing with specific in tems Microleasing regulation.

The main benefit of Microleasing is the attenuation of collateral requirements. FINARCA $y$ Bancentro are adhesion contracts that contain unfair terms as to the responsibility of the Lessor to risks and rights of the lessee.

Keywords: Leasing, grow, development, contract, credit.

* Master en Derecho Empresarial, Pedagoga y abogada, Directora Departamento de Derecho UNAN -Managua 


\section{Introducción}

E 1 contexto socioeconómico incide en las Mipymes no sólo para que adopten decisiones estratégicas, sino también para que incorporen nuevas prácticas de gestión para promover su desarrollo. Existe un amplio consenso entre funcionarios del sector público y privado acerca de la necesidad de fortalecer la capacidad de gestión estratégica de las Mipymes. Desde este ámbito de acción, resulta fundamental reformular las normas jurídicas o adecuar las ya existentes a fin de orientar correctamente los procesos y las iniciativas de apoyo.

El contrato atípico Microleasing, es una forma de Leasing aplicado a las Mipymes. La recomendación para su uso se dio a partir de un estudio en el cual se analizó la viabilidad de la aplicación de este tipo de contrato, en cuatro clases de Mipymes de diferentes sectores del municipio de Masaya. Los aspectos analizados fueron: la capacidad de pago, el historial crediticio y las bondades de este contrato atípico a través de la figura mercantil; además la experiencia del leasing aplicado a los pequeños productores obtenida por el Fondo de Desarrollo Local (FDL).

El Microleasing se erige en un instrumento que favorece la financiación de tipo de empresas pequeñas y medianas. Entre las razones están: no se requiere de nuevas garantías, los créditos oscilan de dos a cinco años, y existen beneficios fiscales que favorecen la aplicación de este tipo de contrato.

\section{Aspectos teóricos contemplados}

En nuestro país el Código de Comercio de 1914 el cual entró en vigencia en 1917, en el título III capítulo I establece las diferentes clases de sociedades mercantiles. Las sociedades civiles se diferencian de las mercantiles fundamentalmente por su finalidad lucrativa.

Las micro, pequeñas y medianas Empresas (Mipymes) en Nicaragua pueden constituirse de acuerdo a sus necesidades, en cualquiera de las formas reguladas por nuestro ordenamiento jurídico. Dichas empresas tienen características de sociedades familiares, en su mayoría han nacido en el seno familiar como una forma de reproducción de trabajos heredados de sus ancestros, las cuales tienen una estructura organizativa conformada por sus miembros, donde se realizan actos de comercio sobre la base de esa estructura familiar. De esa manera el patrimonio es colectivo y se considera dueño o dueña al jefe o jefa de familia.

La importancia de las Mipymes como grupo promotor del desarrollo económico del país, se encuentra en el hecho de ser representante de la mayoría de las empresas. Se ha convertido en la mayor fuente de empleo, contando con gran flexibilidad en sus procesos productivos. A nivel nacional e internacional sus productos tienen una demanda creciente.

La Micro, Pequeña y Mediana Empresa es la unidad económica constituida por una persona natural o jurídica, bajo cualquier forma de organización o gestión empresarial contemplada en nuestro ordenamiento jurídico. Tienen como objeto desarrollar actividades de extracción, transformación, producción, comercio de bienes o prestación de servicios. (art.4 Ley No. 645 publicada el 8 de febrero del 2008). El art. 4 de la Ley de Promoción, Fomento y Desarrollo de la Micro, Pequeña y Mediana Empresa Ley No. 645, establece la clasificación de las Mipymes, señalando que son todas aquellas Micro, Pequeñas 
y Medianas empresas, que operan como persona natural o jurídica, en los diversos sectores de la economía, siendo en general empresas manufactureras, industriales, agroindustriales, agrícolas, pecuarias, comerciales, de exportación, turísticas, artesanales y de servicios, entre otras.

Según las estadísticas proporcionadas en el Plan Nacional de Desarrollo 2012-2016, el $90 \%$ de las empresas nicaragüenses son Mipymes y de éstas el 76\% tiene problemas en cuanto a su legalidad. Se encuentran siempre bajo el Régimen de Pequeños Contribuyentes según Ley de Concertación tributaria (Ley 822 publicada en la Gaceta No 241 diciembre 2012.)

Esta ley de Concertación tributaria, mantiene el impuesto de cuota fija en el título VII, para regímenes simplificados y le llama pequeños contribuyentes. Según el art. 246 es sujeto a este impuesto, las personas naturales que perciban ingresos mensuales menores o iguales a 100,000 còrdobas.

Este tipo de empresas son el motor del crecimiento de nuestro país, representando alrededor del $90 \%$ de la tasa de empleo de acuerdo con información brindada por el Licenciado Gilberto Alcocer, Director de Conimipyme, en entrevista realizada en el noticiero televisivo Canal 2 del 26 de mayo del 2010.

\section{El Arrendamiento financiero o Leasing}

León Tovar (1989:pag.16), considera como fecha de origen de este contrato atípico, el año de1952, como cuna los Estados Unidosy como padreal señor Boothe, en ese entonces director de una fábrica de productos alimenticios en California. Éste al tener que servir un gran pedido de alimentos a la Marina, concibió la idea de alquilar los equipos necesarios para producir tales productos, además del autofinanciamiento de dichos bienes a través de su utilización productiva, calculando adecuadamente la renta. Interpreta la autora que quizás su motivación fue, el hecho de carecer de los suficientes recursos para adquirirlas en compraventa.

Este contrato se aplica en nuestro país sin regulación específica. Actualmente se encuentra en la Asamblea Nacional un Proyecto de ley cuya finalidad es regular el leasing.

\section{Naturaleza jurídica del Arrendamiento financiero}

Existen diversas teorías que explican la naturaleza jurídica del leasing. Entre ellas podemos hacer referencia a las siguientes: teoría del arrendamiento, de la compraventa, del depósito, del mutuo.

La primera de estas teorías analizan el Leasing destacando el contrato como un solo acto; las segundas lo ubica como resultado de la combinación de las acciones de dos contrato contratos típicos. La tercera opinan que se trata de una figura sui géneris, un contrato nuevo.

La teoría del negocio jurídico de financiación, es la que más se aproxima al leasing, señalando que mediante éste contrato se adquiere y mantiene la titularidad durante toda la vida. No es un simple arrendamiento, pues tiene la característica de ofrecer la opción de compra. Tampoco es una compraventa a plazos, dado que en el leasing se da una compraventa. Es en el acto inicial entre el proveedor y el Arrendador el cual concluye con el dominio de este último: el Arrendador no pierde la titularidad del bien, únicamente cede el goce y disfrute del bien. 
El contrato de leasing tiene caracteres que se advierten en la naturaleza de su composición. Javier Arce Gargollo (1999:págs.190-191) destaca los siguientes: atípico, bilateral, oneroso, consensual, principal, conmutativo, a plazos, de tracto sucesivo, irrevocable.

\section{El Microleasing}

La modalidad de Microleasing (Leasing financiero para Mipymes) ha logrado aplicarse con éxito en el sector de pequeños y medianos empresarios para resolver el problema de la escasa o nula garantía que los pequeños productores pueden ofrecer. La introducción del Microleasing desde los años 60 ha permitido incorporar tecnología en los procesos productivos de los pequeños productores. Es una opción importante de financiamiento, de apoyo y fortalecimiento de los productos de crédito ya desarrollados. La propiedad del bien juega un rol importante en el control del riesgo crediticio-financiero (Oviedo Jaime, 2010). Presenta una alternativa de solución al problema de las garantías que los clientes con poco capital, no están en condiciones de ofrecer y que limita su capacidad de endeudamiento.

\section{Regulación del Leasing financiero en Nicaragua}

Según los resultados de entrevistas realizadas a diferentes Mipymes: sector calzado, hamacas, panaderías y textiles, se encontró que en general, el conjunto de normas que regulan este sector no se aplican. Todos ellos señalaron que con la Ley 645 se regularizaron las asociaciones de Mipymes, limitando las posibilidades del desarrollo asociativo, lo cual constituye un efecto adverso. Afirman que las leyes dirigidas a este sector, favorecen a las empresas grandes.
Algunas Mipymes han logrado acceder a un crédito de manera satisfactoria, lo cual indica que ha habido manejo de inversión a través de préstamos de capital de trabajo otorgados por BANPRO, el FDL, FUNDEMI, CARUNA y algunos programas impulsados por el MIFIC. Ahora también el Ministerio de Economía Familiar (MEFCA), se está involucrando en esta dinámica crediticia.

Las Mipymes absorben una porción importante de la población económicamente activa, debido a su gran capacidad de generar empleos. Asimilan y adaptan nuevas tecnologías con relativa facilidad. Cuentan con administración empírica, en muchos casos influenciada por la opinión personal de los dueños del negocio. Han manejado créditos y lo hacen de manera satisfactoria.

Como desventajas se encontró que no se reinvierten las utilidades para mejorar el equipo y las técnicas de producción. Sus ganancias no son elevadas y se mantienen dentro del margen de operación. No contratan personal especializado y capacitado por no poder pagar altos salarios.

\section{Análisis de resultados de revisión documental a Contratos de Leasing financiero}

Algunas instituciones crediticias han venido aplicando el leasing. Ellas han clasificando este tipo de operación como un crédito de consumo.

Al analizar los contratos de Leasing de Financiera Arrendadora Centroamericana S.A. (FINARCA) se encontró que lo definen como un contrato de adhesión, como alquiler con opción a compra. 
Las obligaciones para el Arrendatario son abusivas. En la cláusula sexta, se estipula la renuncia del Arrendatario a pedir resolución del contrato o reducción del canon mientras dure la imposibilidad del uso o goce del bien, aún cuando esta imposibilidad se deba a caso fortuito o fuerza mayor, o algún vicio del bien. En relación a este aspecto la doctrina señala que para eso se debe de recurrir al seguro. El seguro es adquirido por el Arrendatario siendo el beneficiario el Arrendador. Esta misma cláusula establece una disposición en la cual responsabiliza- salvo en caso de culpa grave- al Arrendador sin definir cuando hay culpa grave. El Arrendador, en caso de vicios ocultos en el bien, es responsable.

En cuanto a la cláusula décima segunda, se establece la facultad exclusiva del Arrendador de ceder total o parcialmente el contrato de leasing a terceras entidades, en operaciones de compra de cartera. De acuerdo con la doctrina y algunas legislaciones esto solamente puede hacerse si se pacta de común acuerdo con el Arrendatario.

No se estipulan requerimientos previos para efectos de mora. Los intereses punitorios son establecidos en dólares estadounidenses, incumpliendo así con la Ley orgánica del Banco Central, art. 38, el cual establece que debe de pactarse en córdobas con mantenimiento de valor en relación a la moneda extranjera. El Arrendatario no puede ceder a un tercero las acciones y garantías del contrato. No se establece el mecanismo de solución de controversias. En caso fortuito o fuerza mayor, no establece que será responsable el seguro.

En la cláusula undécima se establece la posibilidad que el Arrendatario no ejerza la opción a compra, debiendo restituir el bien., pero no indica un valor residual, ya que el pago de los cánones es igual. No obstante, establece el mecanismo de solicitud del bien, señalando las características, fijando el domicilio de pago.

\section{Análisis del Contrato de Arrendamiento financiero de Bancentro}

En la cláusula cuarta: (del precio del arrendamiento y la forma de pago) de igual manera que el de FINARCA las cuotas no establecen el valor residual, son cuotas fijas, los pagos anticipados se fijan en moneda extranjera.

En la cláusula quinta: (de las comisiones) el Arrendatario se obliga a pagar a la Arrendadora el 2\% de comisión sobre el Monto del Contrato, una comisión del uno por ciento $(1 \%)$ sobre el saldo anual del contrato, en concepto de administración del arrendamiento que se pagará al finalizar cada año contractual y pagará el cero punto cinco por ciento $(0.5 \%)$ en concepto de honorarios legales. En caso de mora, el Arrendatario pagará un interés del dos por ciento $(2 \%)$ mensual. Asimismo, se le cobrará por concepto de gastos administrativos, la cantidad de cincuenta (50) dólares estadounidenses al momento de iniciar el arrendamiento financiero.

En este contrato se encuentra una diferencia con el anterior, y es que establece la obligación del Arrendatario a suscribir un contrato de mantenimiento del bien arrendado, para así garantizar el óptimo mantenimiento y funcionamiento del mismo, durante la vigencia del contrato. En la cláusula sexta, se establece la inspección anual del bien en arrendamiento.

Al analizar la cláusula octava sobre la responsabilidad del bien arrendado, se establece que no será motivo de suspensión 
de pago del canon de arrendamiento, si el bien arrendado no funciona o no puede ser utilizado por desperfectos de cualquier naturaleza. Esta cláusula es demasiado general y deja en indefensión al Arrendatario, por hecho que al recibir a su entera satisfacción el bien arrendado y constatar su buen estado, renuncia al derecho de garantía por evicción o vicios ocultos o redhibitorios y libera a la Arrendadora de esa obligación de garantía y saneamiento.

En la cláusula décima: (del seguro y la ubicación del bien arrendado) el Arrendatario se obliga a contratar por su exclusiva cuenta, cubriendo todos los gastos, inclusive el pago del deducible, que se demande en cualquier caso, en los términos que establezca la aseguradora, un "Seguro Contra Todo Riesgo" hasta por una suma equivalente en moneda extranjera US\$ ( ) (de los Estados Unidos de América), al valor comercial del bien arrendado, estableciendo como beneficiaria del seguro a la Arrendadora.

La opción de compra: cinco días hábiles después de expirar el plazo el contrato, el Arrendatario puede ejercer la opción de compra; caso contrario devolverá el bien arrendado a la Arrendadora, quedando las sumas pagadas a cuenta del arriendo sin derecho a ninguna devolución; de la misma manera, podrá el Arrendatario celebrar un nuevo contrato de arrendamiento en los términos, plazos y condiciones que fije la Arrendadora. (Cláusula décima tercera)

Cláusula décima cuarta: (de la cesión total o parcial del contrato). Queda convenido que el Arrendatario no podrá ceder o traspasar total o parcialmente por cualquier título los derechos que este contrato le otorga, ni podrá sub-arrendar los bienes arrendados sin el consentimiento previo y expreso de la Arrendadora.
La cláusula décima quinta expresa el incumplimiento por parte del Arrendatario, la falta de pago de los cánones de arrendamiento, hará incurrir automáticamente en mora al Arrendatario y a partir del día siguiente de producirse la falta de pago, queda facultada la Arrendadora para hacer exigible, a su elección:

a) La rescisión del contrato, con la devolución de los bienes arrendados a entera satisfacción de la Arrendadora y el pago de los daños y perjuicios que ocasionen.

b) La ejecución del contrato, mediante el pago de la totalidad de los cánones de arrendamiento vencidos o que están por vencerse, hasta la fecha pactada para la terminación del contrato.

c) Encasocontrario,la Arrendadoraacepta en forma irrevocable la resolución de pleno derecho del contrato con el pago de los daños y perjuicios pertinentes y sin que para este hecho se tenga que recurrir a declaratoria alguna por parte de los Tribunales de Justicia. Ante el incumplimiento la Arrendadora tomará posesión del bien.

d) El monto que adeuda el Arrendatario por este concepto, deberá estar acreditado mediante certificación librada por Contador Público Autorizado o por el Auditor de la Arrendadora y podrá ser cobrado por la Arrendadora por la vía ejecutiva, sin necesidad de ningún requerimiento previo.

e) La Arrendadora tendrá derecho a cobrar a título de daños y perjuicios, un interés penal del veinticinco $(25 \%)$ por ciento anual sobre los cánones vencidos no pagados, sin perjuicio de la exigibilidad de la resolución del 
contrato o del cobro ejecutivo, tal como se establece en las cláusulas anteriores.

Se identificó en la Cláusula décima novena, el abuso por parte del Arrendador en cuanto a las renuncias:

- A su domicilio, sometiéndose al que la Arrendadora elija.

- A cualquier aviso o requerimiento, la mora se producirá por el simple retraso en el cumplimiento de sus obligaciones.

- A las excepciones provenientes de caso fortuito o fuerza mayor, cuyos riesgos asume desde la firma del contrato por imprevistos o inesperados que sean.

- A la invocación de prórrogas tácitas o renuncias por cualquier acto que las hiciera presumir.

- A los trámites del juicio ejecutivo corriente.

- A las Penalizaciones por falta de pago.

\section{Experiencias del FDL en la aplicación del Microleasing}

La Asociación Fondo de Desarrollo Local (FDL) dispone un 10\% de su sector meta para los micro, pequeños y medianos empresarios rurales de producción, comercio y servicios, que son viables económicamente pero que no tienen acceso al sector bancario formal. "En Nicaragua existen alrededor de 200 mil pequeños y medianos productores rurales que no son sujetos de crédito de la banca. Se están financiando unos 13 mil productores, en el sector urbano se estima que puede haber alrededor de 350 mil pequeños y medianos comerciantes y productores, clientes de servicio, pequeña industria y asalariados", aseguró Reyes gerente de Mercadeo FDL.
Según Eva García, Gerente Comercial, el FDL además de otorgar créditos a los pequeños productores, les brinda asesoría técnica y capacitación, la cual es financiada por el mismo FDL. Por otra parte, suelen realizar alianzas estratégicas con comercializadoras.

Como productos financieros emplea el Microleasing en Riego, consistente en la compra de los equipos por parte de la institución los cuales son entregados en arriendo a los productores con opción de compra a intereses muy bajos. También dan crédito ganadero, agrícola, comercial, de consumo, para vivienda, para servicios, a la pequeña industria y crédito para inversión productiva.

El acceso a crédito crea una base sólida de crecimiento económico y desarrollo social, al poner en las manos de los productores y las pequeñas empresas, una herramienta para el logro de sus planes productivos y de mejoramiento de sus condiciones de vida.

De acuerdo con entrevista realizada al gerente de operaciones financieras, Licenciado Oscar Manzanares, de esta experiencia, uno de los elementos a destacar, es la asociación de los Proveedores y el agente financiero quienes hacían posible las capacitaciones a los campesinos en el sector del riego sobre el uso de la maquinaria.

\section{Conclusiones}

El leasing o Arrendamiento financiero es un instrumento que se ha utilizado para financiar bienes, fundamentalmente muebles. Las Mipymes muestran, en términos generales, falta de capital de trabajo, aspecto que limita sus posibilidades de acceso a un financiamiento adecuado a 
sus necesidades, siendo el Microleasing una alternativa práctica viable para su desarrollo.

1. Existen Acuerdos Ministeriales en materia de exención de impuestos para este sector, así como, la Ley de Concertación Tributaria y otras leyes, que favorecen la aplicación del Microleasing. Se hace necesaria la inclusión en el proyecto de Ley de Leasing de artículos específicos, para la regulación del Microleasing, que garantice su aplicación en las Mipymes.

2. El principal beneficio del Microleasing es la atenuación de los requerimientos de garantía, porque el bien arrendado constituye la garantía en sí misma. La clave del éxito de la aplicación de las experiencias del Microleasing han sido: el monitoreo y la asistencia técnica.

3. Los contratos de Leasing utilizados por Finarca y Bancentro son contratos de adhesión, contienen cláusulas abusivas en cuanto a la responsabilidad del Arrendador sobre los riesgos, derechos del Arrendatario, en los cuales se destacan la renuncia al domicilio, ausencia de mecanismos de resolución de conflictos, falta de definición de causales de rescisión del contrato. Las exenciones fiscales no son trasladados al valor del bien. No cumplen con las leyes de protección al consumidor, no establecen ningún requerimiento previo para los efectos de la mora y dejan establecida la vía ejecutiva en caso de retrasos en los pagos.

4. La Arrendadora del Microleasing logra mejores condiciones en la compra de equipos como menores precios, ampliación de tiempos de la garantía y mejores servicios post-venta.

\section{Recomendaciones}

1. Le corresponderá al Ministerio de Economía Familiar el apoyo a la Pequeña y Mediana Empresa la promoción de este tipo de contrato y asegurar la incorporación de los artículos sugeridos por el estudio, en el Proyecto de Ley.

2. Ampliar el objeto del Proyecto de ley a fin de regular las operaciones de Microleasing dirigidas a las Mipymes.

3. Definir el contrato de Microleasing que incluya obligaciones de las partes y derechos, incluir al Proveedor.

4. Ampliar el capítulo de la aceptación, incluir la transmisión del riesgo. Darle el tratamiento debido a los daños y perjuicios.

5. De los beneficios fiscales.

6. Abordar las formas de la rescisión del contrato. Las formas de dirimir las controversias. Tratamiento procesal

7. Incluir el seguro.

\section{Referencias Bibliográficas}

Amador Carlos (2004) Informe del Cuarto Congreso Nacional Pyme Editorial INPYME Managua, Nicaragua.

Broseta Pont, Manuel (1977) Manual de Derecho Mercantil, Editorial Tecnos S. A. $3^{a}$ edición España 792 págs.

Gargollo Arce Javier (1999) Contratos mercantiles Atípicos. Editorial Porrúa, Sexta Edición, México 446 págs. 
Herrera Espinoza Jesús (2010) Contratos Atípicos, Maestría en Derecho Empresarial, UNAN-MANAGUA Editorial Universitaria, Managua Nicaragua.

León Tovar, Soyla (2004) Contratos Mercantiles, Colección Títulos Jurídicos Universitarios, Edición Oxford University Press, México S.A. págs.826

Ministerio de Fomento, Industria y Comercio (2008) Programa de crédito para Capital de Trabajo, Infraestructura y Adquisición de Maquinaria y Equipos, Caruna Octubre 2008, MIFIC, Managua, Nicaragua.

Orúe Cruz, José René (2008). Manual de Derecho Mercantil 2a Edición Editorial Hispamer, Managua,
Somarriba Jarquín Francisco, (2008.) Derecho Bancario, Impresiones Helios. Universidad Centroamericana (UCA) 325 págs. Managua. Nicaragua.

Valdés Rodríguez Gilbert (1999) La Pyme Industrial en Nicaragua editado por el MIFIC Managua Nicaragua 143 págs.

Código de Comercio de la República de Nicaragua, publicado en "La Gaceta" $\mathrm{N}^{\mathrm{o}} 144$ de 8 de julio de 1916.

Ley 645, Ley de Promoción, Fomento y Desarrollo de la Micro, Pequeña y Mediana Empresa publicada el 8 de febrero del 2008. Y su Reglamento.

Ley No. 822, Ley de Concertación Tributaria Publicada en la Gaceta Diario Oficial. Dic. 2012. 